\title{
Upper thermospheric ion-neutral coupling from combined optical and radar experiments over Svalbard
}

\author{
E. M. Griffin, A. L. Aruliah, I. McWhirter, H.-C. I. Yiu, and A. Charalambous \\ Atmospheric Physics Laboratory, University College London, UK \\ Received: 8 March 2009 - Revised: 28 September 2009 - Accepted: 22 October 2009 - Published: 26 November 2009
}

\begin{abstract}
The response of thermospheric neutral parameters such as winds and temperatures to rapid changes in geophysical conditions has usually been considered to be relatively slow, on the order of hours, and steady, representing an integration of more rapid ionospheric changes. Quantifying the relevant ion-neutral coupling has proved difficult due to a lack of relevant laboratory data for the most important collisions, namely between neutral atomic oxygen and its first ion. As a result the representation of ion-neutral coupling in numerical models of the upper atmosphere has often produced poor comparison to experimental data. Using a unique combination of spatially extended ion and neutral thermospheric parameters we show that the neutral response can be very rapid, within $15 \mathrm{~min}$, to imposed forcing via ion-neutral coupling. The array of complementary instrumentation measuring the thermosphere above Svalbard in the Northern Hemisphere allows detailed study of the causes and effects from both the ion and neutral perspectives. The implications for development and testing of the thermospheric numerical models is discussed.
\end{abstract}

Keywords. Ionosphere (Ionosphere-atmosphere interactions; Polar ionosphere) - Meteorology and atmospheric dynamics (Thermospheric dynamics)

\section{Introduction}

Electric fields and particle precipitation can strongly alter the state of the upper atmosphere, most notably in the polar regions. The influence of the solar output is translated into these terrestrial geophysical effects via the magnetosphere. While the ionosphere is expected to respond to these changes dramatically and rapidly the thermosphere has been viewed

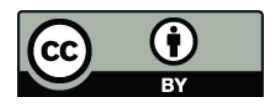

Correspondence to: E. M. Griffin

(eoghan@apl.ucl.ac.uk) as a passive ultimate sink of the input energy, responding on far longer time scales and with relatively small perturbations in winds and temperatures. This view of a smoothly behaving thermosphere has resulted in model representation of the neutral atmosphere which only considers gross structure and long response times for the thermosphere. This is true of both the self consistent 3-D numerical coupled ionosphere and thermosphere models such as CTIM (Fuller-Rowell et al., 1996) and TIME-GCM (Roble, 1996) as well as the empirical models available such as MSIS (Hedin, 1991) and HWM (Hedin et al., 1991).

Heelis et al. (2002) have used a 6 day time series of ion and neutral parameters, together with the relevant time series of IMF conditions, to derive response times for the ionosphere and thermosphere to changes in solar forcing. The results indicated a response time for the thermosphere which was $55 \mathrm{~min}$ later than that of the ionosphere, appearing to confirm the picture of the thermosphere as a slow-moving passive sink of energy. It should be noted however that while the best overall fit between the parameters over the 6 days produces a long response time this does not preclude the possibility of shorter response times to individual events, and should not be taken as a lower limit to the thermospheric response time. Also the results reflect the time taken for the ionosphere and thermosphere to reach a "steady state" after the impact of changes in the solar wind drivers.

Burnside et al. (1987), Davis et al. (1995) and many other authors have investigated the accuracy of estimates of the thermospheric ion-neutral collision frequency by combining optical and radar experiments and inverting velocity results to produce a best fit to the collision frequency. Unfortunately the paucity of relevant experiments and difficulty in attributing reasonable estimates of errors and together with other factors has resulted in a lack of consensus as to the most reliable figures.

Numerical model results have produced overestimated thermospheric neutral winds and underestimated neutral

Published by Copernicus Publications on behalf of the European Geosciences Union. 


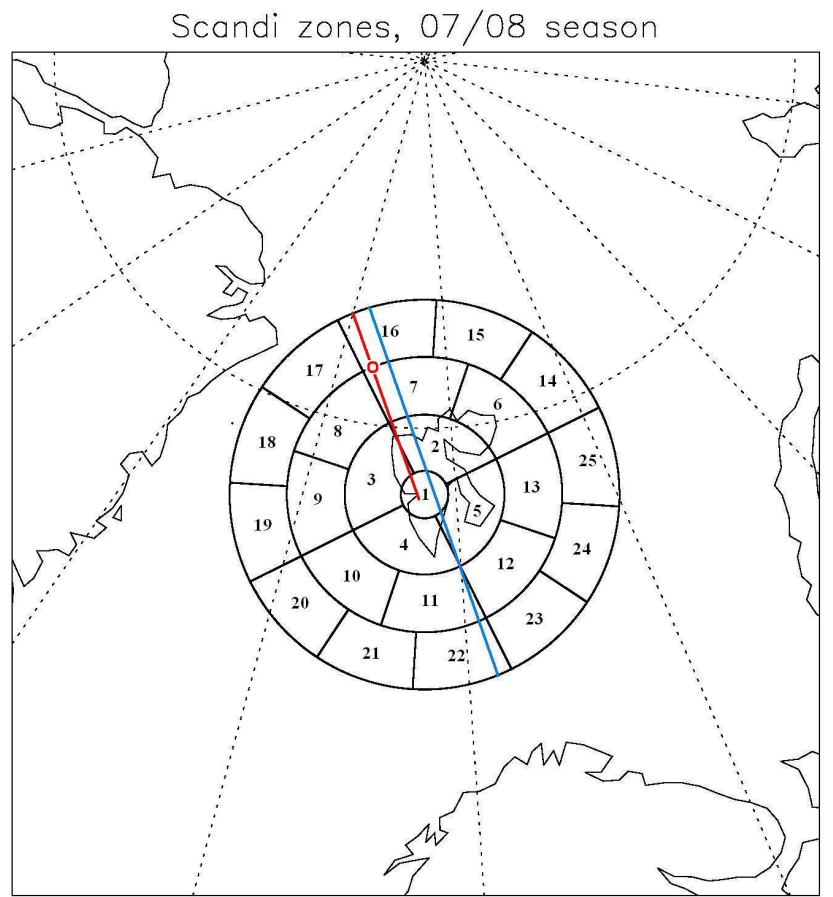

Fig. 1. Map showing SCANDI field-of-view divided into 25 zones covering a latitude range $74^{\circ}-82^{\circ} \mathrm{N}$.

temperatures in a number of comparisons to experimental data (e.g. Dobbin et al., 2006). Some of these discrepancies are believed to be due to a lack of consideration of small scale structure as the models have large grid point separation in latitude and longitude, however it is likely that the estimates of fundamental factors such as the ion-neutral collision frequency, used to calculate the effects of ion-neutral coupling, are also a source of error. Moreover the degree to which small scale structure requires representation in some form in the model construction relies on accurate knowledge of the relevant timescales and magnitudes for ion-neutral coupling (Codrescu et al., 2000).

Many studies in recent years have pointed to the possibility of rapid thermospheric responses to changes in geophysical parameters and subsequent evidence for mesoscale thermospheric structure (e.g. Aruliah and Griffin, 2001; Aruliah et al., 2004, 2005). As radars have revealed new scales of ionospheric structure new optical instrumentation, such as the Scanning Doppler Imagers (Conde and Smith, 1997), have been developed to investigate the details of thermospheric spatial structure. The SCANDI instrument has been installed on Svalbard to further these studies in combination with the EISCAT Svalbard Radar (ESR) and Cutlass coherent scatter radars in Finland and Iceland, part of the SuperDARN radar network. It has been recently used to demonstrate evidence of the structure within the extended field of view (FOV) provided by this type of instrument (Griffin et al., 2008).
Combining this instrumentation, in this paper we investigate the rapid and local thermospheric response to ionospheric forcing, the driving mechanism behind the observed thermospheric features and the implications for modelling the coupled ionosphere and thermosphere.

\section{Instrumental configuration}

Atmospheric Physics Laboratory at University College London (APL) has operated Fabry-Perot Interferometers (FPIs) at Svalbard since 1982 and at the new Kjell Henriksen Observatory (KHO), near Longyearbyen, a standard FPI and new Scanning Doppler Imager (SCANDI) were installed in November 2007. Both instruments are capable of making measurements of thermospheric winds and temperatures but differ in their FOV. When combined with the radar coverage provided by the EISCAT Svalbard Radar, measuring ionospheric velocities, temperatures and densities, and twin Cutlass coherent scatter radars, measuring ionospheric velocities over a wider FOV, a fuller picture of thermospheric parameters may be determined above Svalbard than at any other high latitude site.

The SCANDI instrument has been described in Griffin et al. (2008) and allows spatially extended measurements of thermospheric winds and temperatures within an all-sky FOV of $120^{\circ}$. The design of the SCANDI instrument allows a free choice of sampled regions within the FOV, the limiting factor being the integrated intensity, and hence profile definition, achievable within smaller sectors. The 25 zone configuration as shown in Fig. 1 was implemented after the instrument was moved to the $\mathrm{KHO}$ and was in operation on 5 December 2007. Operating in parallel with SCANDI was the co-located FPI. Each of the cardinal look directions of the FPI, sampled at $30^{\circ}$ elevation and with a $1^{\circ} \mathrm{FOV}$, overlap with one of the SCANDI zones. North from the FPI is contained within SCANDI zone 16 as shown in Fig. 1, South within zone 22, East within zone 25 and West within zone 19. These outer SCANDI zones each contain a range of elevations from $23^{\circ}$ to $40^{\circ}$ and extend through $30^{\circ}$ of azimuth. The approximate scales when projected to the $630 \mathrm{~nm}$ atomic oxygen emission altitude of $250 \mathrm{~km}$ are $220 \mathrm{~km}$ between the centres of each zone.

The fields of view of the Cutlass radars positioned in Iceland and Finland converge over Svalbard and complement the detailed, high time resolution point measurements possible with the ESR (Yeoman et al., 2000). The projected beam paths for the Cutlass Finland beam 10 (blue) and the pointing direction of the ESR $32 \mathrm{~m}$ dish (red), from the experiment running after 08:10 UT on the morning of 5 December 2007, are also plotted on Fig. 1. In addition KHO is equipped with multiple optical systems to monitor auroral conditions and weather and there are several magnetometer stations measuring within the SCANDI FOV. 

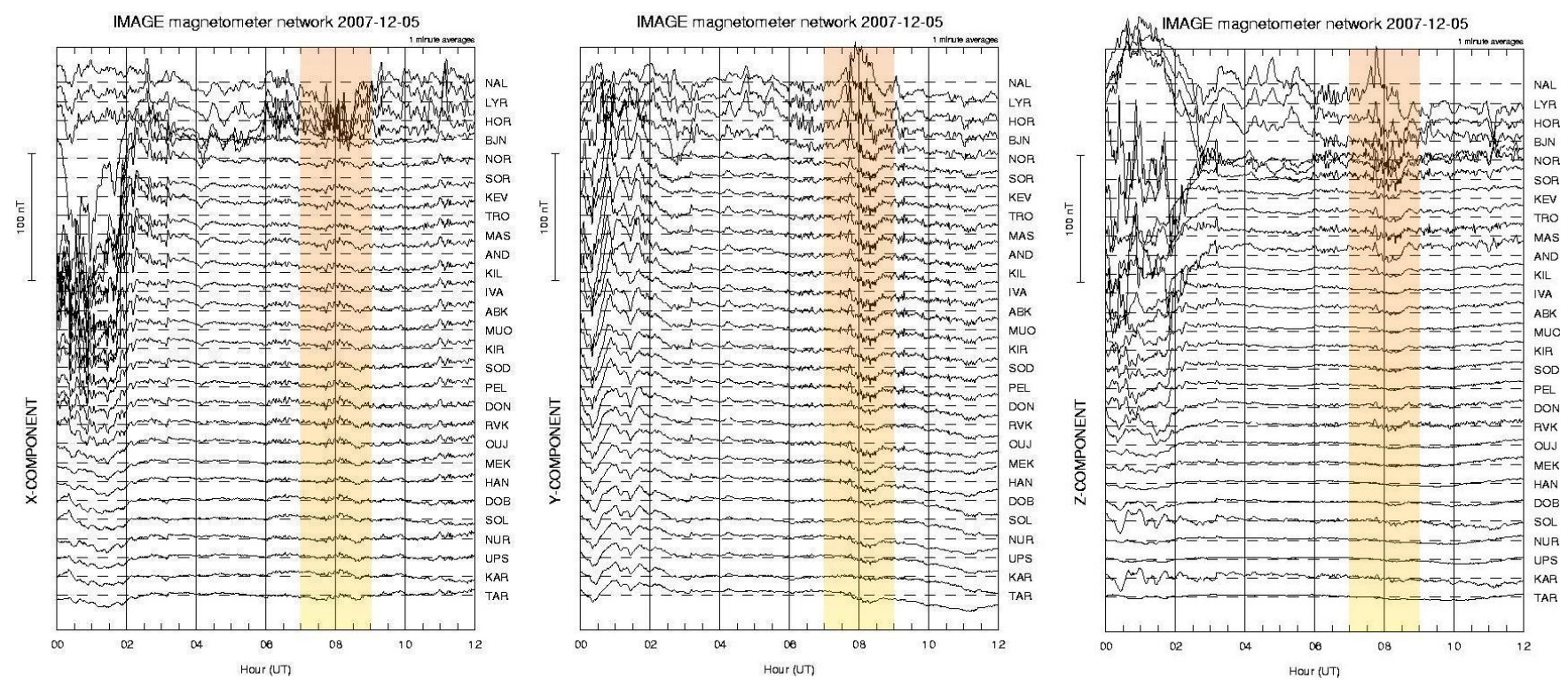

Fig. 2. IMAGE magnetometer chain data for the period 00:00-12:00 UT on 5th December 2007 seperated into (a) X-component, (b) Ycomponent and (c) Z-component. In each subplot the period from 07:00-09:00 UT is highlighted.

\section{Results from 5 December 2007}

Late November and early December 2007 were characterised by very low solar and geomagnetic activity levels. From 27 November 2007 to 5 December 2007 daily $A_{p}$ never rose above 5 and only registered a value of 1 for both 3 December 2007 and 4 December 2007. The F10.7 index varied from 69.2 to 73.1 through the same period.

\subsection{ACE satellite and IMAGE magnetometer chain data}

The local magnetometer traces from the IMAGE chain (Lühr, 1994) for the period 00:00-12:00 UT on 5 December 2007 are shown in Fig. 2. Between 03:00-05:00 UT the magnetometer traces from all sites below Nordkapp (NOR) are fairly flat, the disturbance is clearly confined to the magnetometers north of about latitude $71^{\circ}\left(\mathrm{CGM}\right.$ lat $\left.68^{\circ}\right)$. Around 07:30 UT there is a small sharp disturbance $(<50 \mathrm{nT})$ localised mainly over the stations between Bjornoya (BJN) and Ny Alesund (NYA), which are the 4 northern-most stations. The magnitude of the disturbance increases to the North. The $B_{x}$ traces (Fig. 2a) indicate westward ionospheric currents over Svalbard, and the $B_{z}$ traces (Fig. 2c) indicate that the currents are centred between Longyearbyen (LYR) and NYA. The $B_{y}$ component (Fig. 2b) indicates a northward current component, increasing in magnitude to the North.

The ACE satellite upstream solar wind IMF data (GSM coordinates) for the period 05:00-07:30 UT on the 5 December 2007 are plotted in Fig. 3. The IMF is large and begins this period oriented along the positive z-direction until it turns negative around 06:40 UT. $B_{z}$-negative is sustained for around $50 \mathrm{~min}$ before turning positive again. Previous to the negative turning is a brief positive jump in $B_{z}$ ob- served during the period between 06:20-06:40 UT, when the $B_{y}$ component increases from $+2 \mathrm{nT}$ to over $+6 \mathrm{nT}$. The $B_{y}$ component is large and negative from 05:30 UT, but briefly decreases from $-8 \mathrm{nT}$ to $-6 \mathrm{nT}$ exactly when the $B_{z}$ component increases. The total IMF magnitude is slowly reducing, so this feature appears to be a brief twist in a field that is otherwise rotating anticlockwise until about 06:28 UT. By using the average of the solar wind velocity in the $\mathrm{x}$-direction, and the location of ACE in the x-direction over the period 06:00 to 08:00 UT, a simple estimate of the lag time from ACE to the magnetopause is calculated as about $1.13 \mathrm{~h}$, which means that this brief feature arrives at Earth around 07:25 UT. This timing is consistent with the ground magnetometer deflections observed by IMAGE.

\subsection{Thermospheric winds and temperatures}

Figure 4a shows the neutral winds recorded by the Svalbard FPI from 05:00 UT to 12:00 UT from the North, East, South, West and Zenith look directions. Winds are plotted positive northward, eastward and upwards. Of note is the clear northward surge in winds from 07:45 UT to 09:00 UT which is seen solely in the samples recorded to the North. The northward wind is nearly $100 \mathrm{~m} / \mathrm{s}$ larger than the background wind values both before and after the event. It is also evident that no surge of any significance is recorded in the observations of winds from the South. Figure $4 \mathrm{~b}$ shows the corresponding $630 \mathrm{~nm}$ intensities which show a sharp rise in intensities seen only to the North and West look directions at the same time as the northward surge. This appears to show the feature to be highly localised to the North-West quadrant of Longyearbyen. 


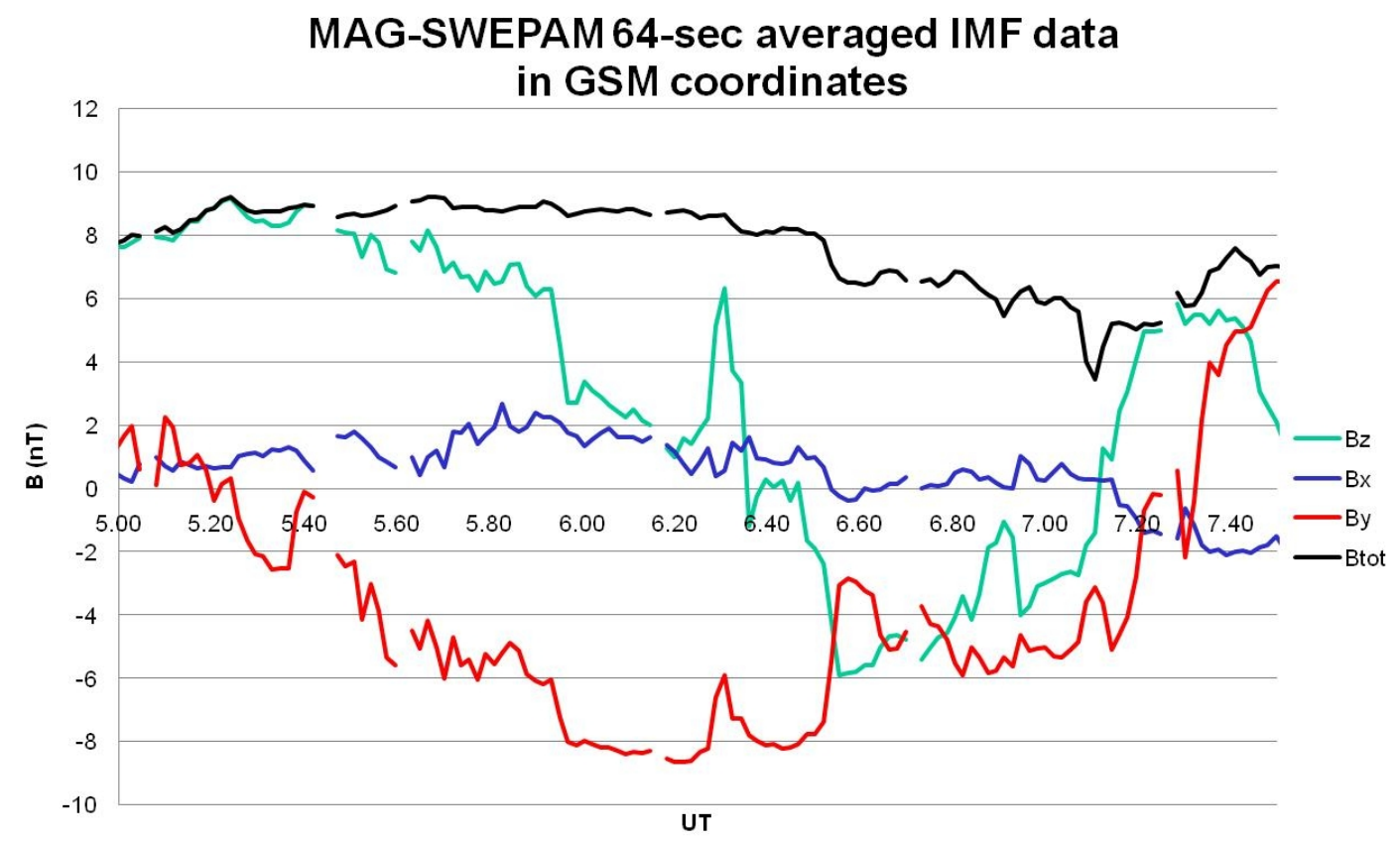

Fig. 3. ACE magnetometer data showing $64 \mathrm{~s}$ averages of the IMF in GSM coordinates.

Figure 5 shows the SCANDI neutral temperature (Tn) measurements from all 25 zones from 05:00-12:00 UT. There is a persistent spread of around $50 \mathrm{~K}$ over the FOV for the whole period that is plotted. Just after 07:30 UT there is a clear trend in the temperature over the whole FOV. A sharp increase in temperature is observed in all zones, appearing to begin around 07:45 UT and resulting in an overall increase in Tn of around $100 \mathrm{~K}$ that peaks at around 08:20 UT. Subsequently a slow decrease in temperature is observed in all zones until 11:00 UT.

Figure 6a shows the modelled MSIS-E Tn at $240 \mathrm{~km}$ for the longitude $16^{\circ} \mathrm{E}$ and a latitude range $70-86^{\circ} \mathrm{N}$. The actual F10.7 and $K_{p}$ parameters over the period 05:00-12:00 UT on 5 December 2007 were used in determining Tn using the available modelling tools (MSIS-E website). As is wellknown, MSIS-E is a semi-empirical model created by fitting spherical harmonics to databases of mass spectrometers and incoherent scatter radar data (e.g. Hedin, 1991). It is an extremely useful model, but as with all such global models, requires care in its use. Small scale activity, spatially and temporally localised as seen in this case study, should not be expected to be modelled well. The MSIS-E temperatures change smoothly with time and latitude and do not show the sharp temperature increase caused by the flurry of geomagnetic activity. The trend is gently upwards from $630 \mathrm{~K}$ (all latitudes) to a maximum of $690 \mathrm{~K}$ (at $70^{\circ} \mathrm{N}$ ) during the period 05:40-12:00 UT. The MSIS-E temperature at $78^{\circ} \mathrm{N}$ is generally $75 \mathrm{~K}$ lower than the mean SCANDI Tn. If a peak emission height of $240 \mathrm{~km}$ is assumed the SCANDI FOV has a diameter $\sim 1000 \mathrm{~km}$, which is approximately the latitude range $70^{\circ} \mathrm{N}-86^{\circ} \mathrm{N}$. The spread in Tn between these latitudes is at most $45 \mathrm{~K}$ at 12:00 UT but practically zero be- tween 05:00-06:00 UT. In contrast the SCANDI data from all zones show a consistent spread of around $50 \mathrm{~K}$ throughout the period shown.

Figure $6 \mathrm{~b}$ shows the MSIS-E height dependence of Tn for the hours 05:00-09:00 UT. From just above an altitude of around $200 \mathrm{~km}$ the positive temperature gradient with altitude reduces dramatically, becoming isothermal with respect to height by $300 \mathrm{~km}$. Models of the $630 \mathrm{~nm}$ emission profile indicate that particle precipitation could push the nighttime emission peak down below $240 \mathrm{~km}$, but at lower altitudes quenching by collisions with molecular nitrogen means that the peak is unlikely to descend far below $200 \mathrm{~km}$ (Rees and Roble, 1986). A temperature drop of $50 \mathrm{~K}$ would represent a drop in altitude of around $70 \mathrm{~km}$, which means a emission peak sampling an altitude of between $150-180 \mathrm{~km}$, which is unlikely.

Figure 7a plots the same SCANDI temperatures shown in Fig. 5, but in a keogram format to show the time dependence of Tn and also the spatial dependence. The data are taken from the SCANDI sectors 15, 6, 7, 1, 4, 10, 11, 21, which represent a slice from north to south, covering a latitude range $74^{\circ}-82^{\circ} \mathrm{N}$. The keogram format allows direct comparison with Fig. $7 \mathrm{~b}$ which shows the equivalent currents derived from the MIRACLE magnetometer chain. A box is drawn around the region that is common to Fig. 7a and $\mathrm{b}$, namely the latitude range $74^{\circ}-80^{\circ} \mathrm{N}$ and time $06: 00$ 09:00 UT. At 08:00 UT Fig. 7b shows there is a large surge in current within latitudes $75^{\circ}-78^{\circ} \mathrm{N}$, and Fig. 7a shows a rise of $100 \mathrm{~K}$ in Tn occurring $20 \mathrm{~min}$ later and covering the whole SCANDI FOV. Interestingly the peak temperatures are to the far ends rather than the central region of current flow. 

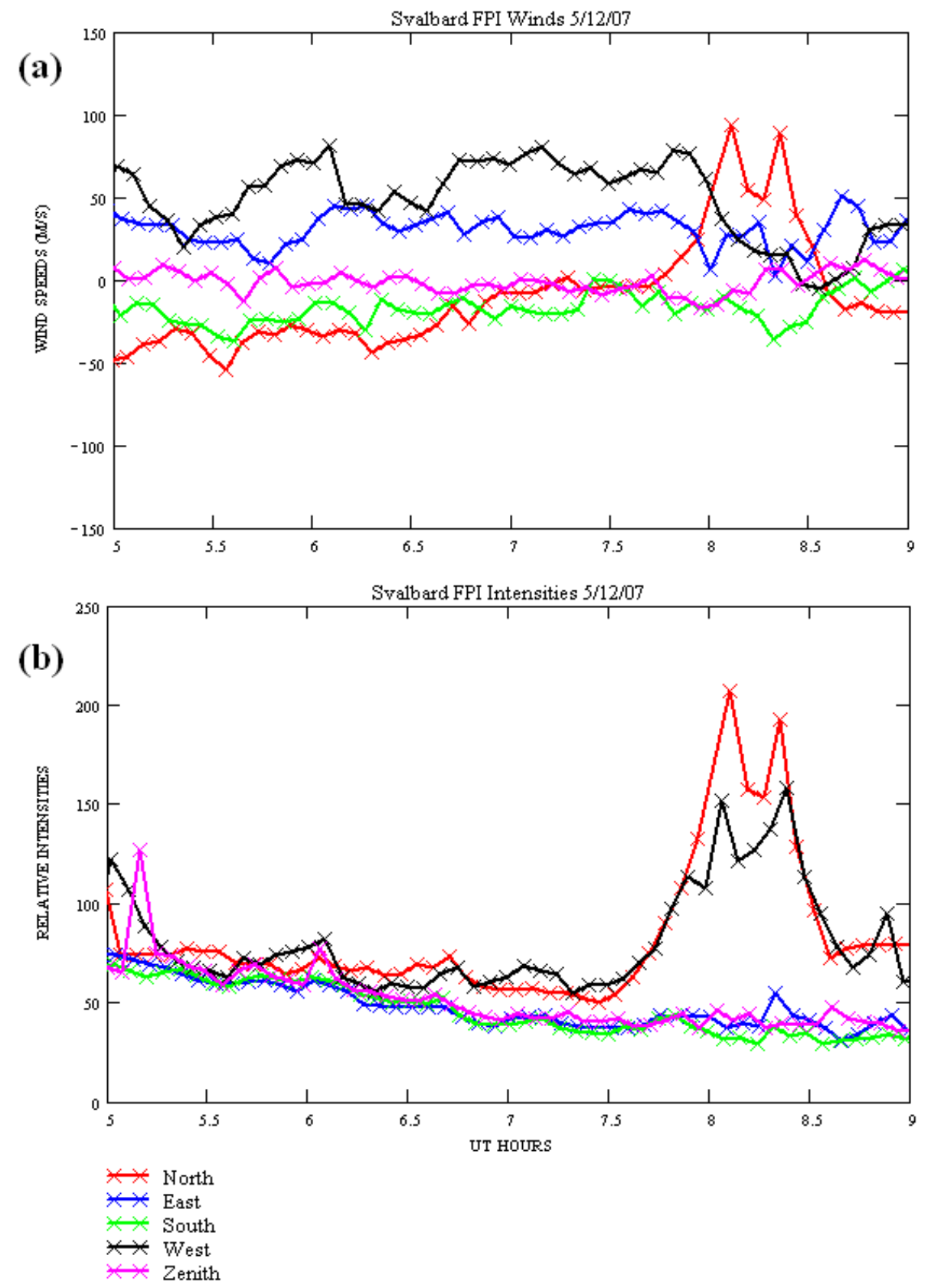

Fig. 4. Svalbard FPI results for 5 December 2007 from 05:00 to 09:00 UT showing (a) wind velocities, positive northward and eastward, containing a sudden surge in meridional wind component only to the north and not to the south around 08:00 to 08:30 UT; (b) FPI intensities with peaks to the north and west at the time of the surge in the meridional wind.

\subsection{Ion velocities from Cutlass SuperDARN radars}

The Hankasalmi Cutlass coherent radar, with an FOV extending over Svalbard from Finland, did not observe any scatter before 07:51 UT, however once velocities were observed from scatter from this period onwards strong northward flows were measured. Figure 8 a shows the ion velocities, plotted as a function of latitude and time, from 07:40 UT to 09:40 UT from beam 10 of the radar. This beam is projected on Fig. 1 in blue and is aligned in a NNW direction. Strong highly spatially localized flows, reaching northward line-of-sight (LOS) values around $800 \mathrm{~m} / \mathrm{s}$, are evident immediately from 08:10 to $08: 15$ UT and gradually reduce to much smaller velocities by $08: 30$ UT. Figure $8 b$ shows the spatial extent of these flows at 08:15 UT, peaking to the NNW of Longyearbyen. 


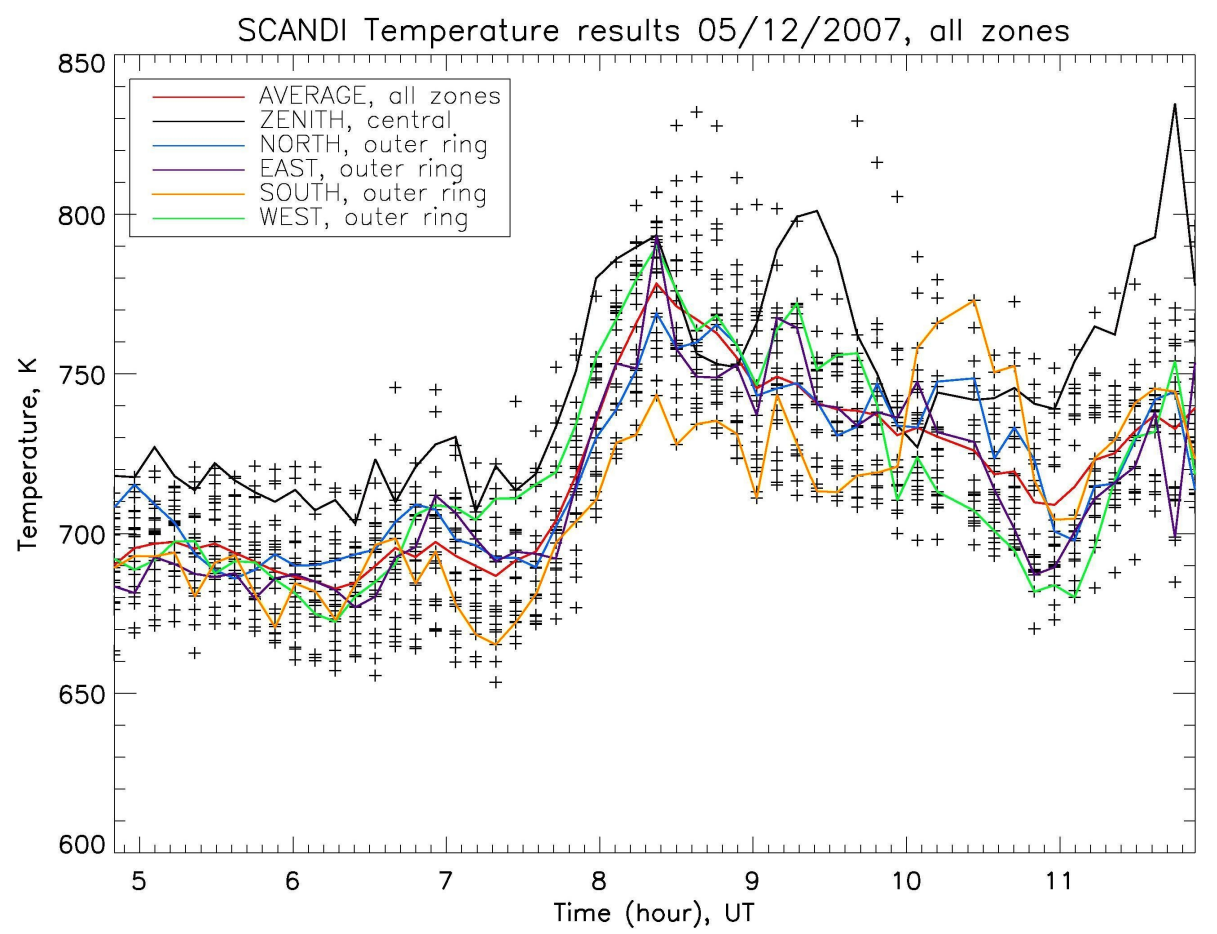

Fig. 5. Time dependence of the SCANDI neutral temperatures from all 25 zones for 05:00-12:00 UT on 5 December 2007.

6a) MSIS-E 5th Dec 2007 $\operatorname{Tn}(240 \mathrm{~km})$ at latitudes $70-86 \mathrm{~N}$ and longitude $16 \mathrm{E}$

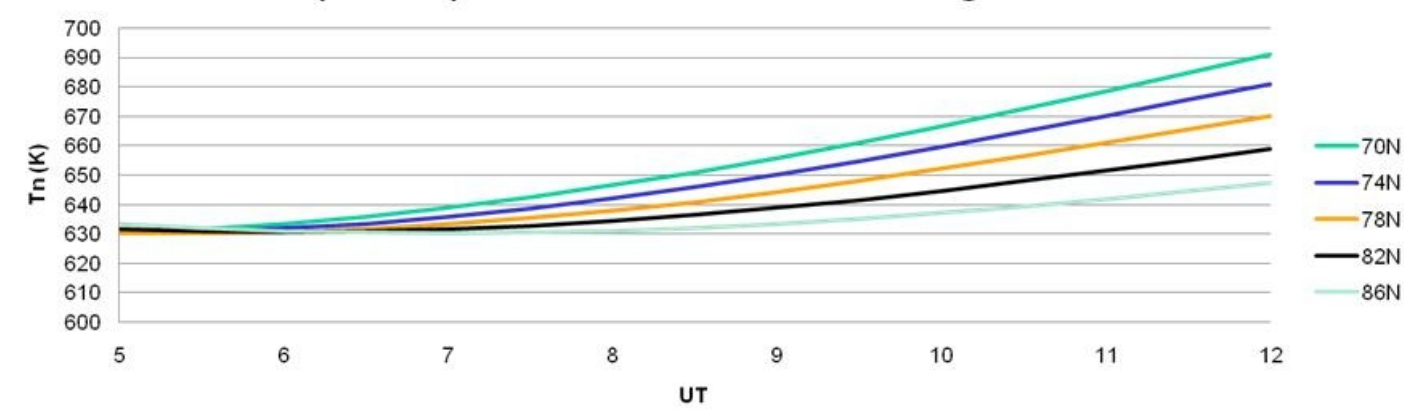

6b) MSIS-E 5th Dec 2007 altitude dependence of $\mathrm{Tn}$ at $78 \mathrm{~N}, 16 \mathrm{E}$ for the period 05-09UT

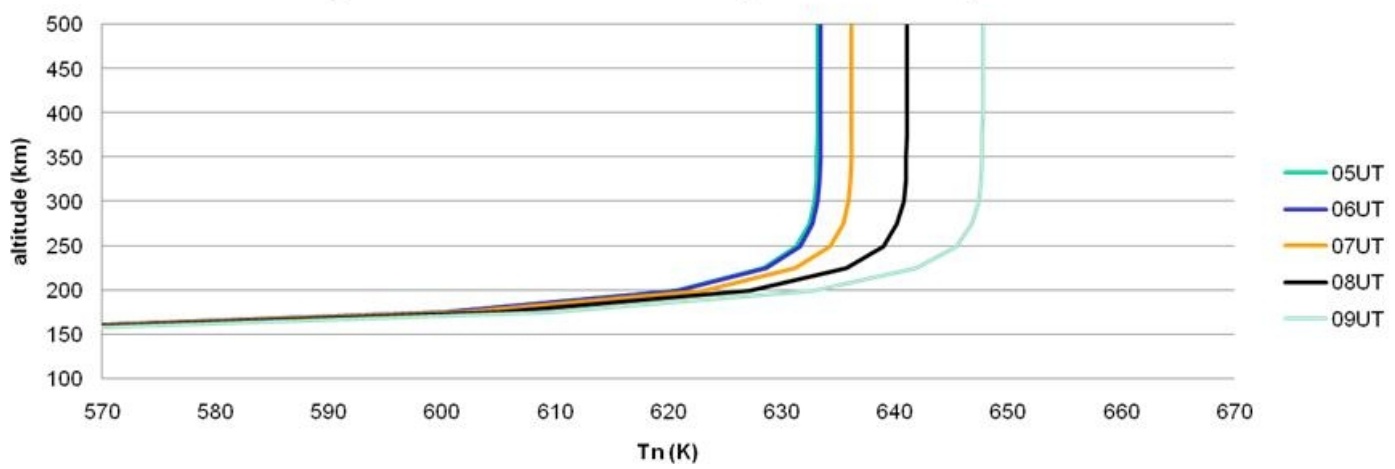

Fig. 6. Corresponding temperatures from the MSIS-E semi-empirical model for measured temperatures in Fig. 5 by (a) latitude and (b) height. 

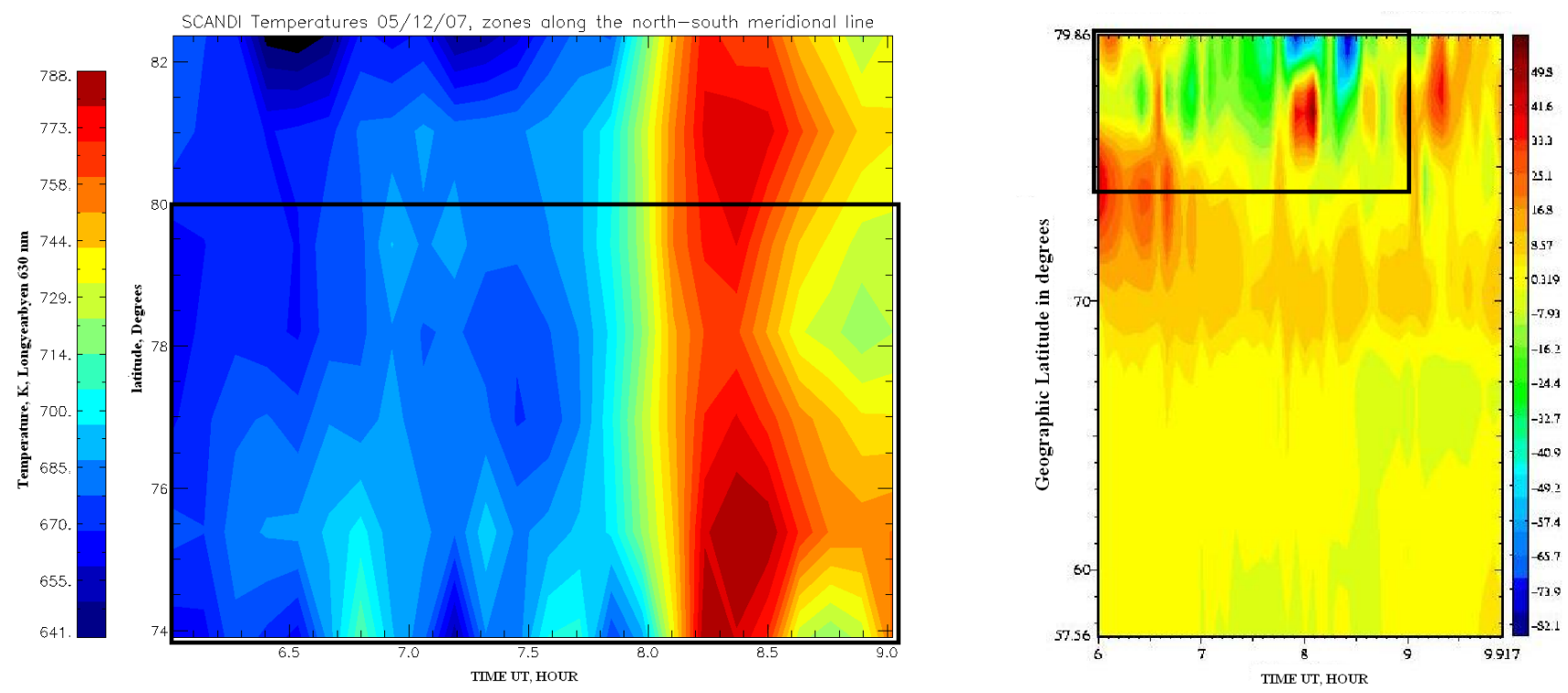

Fig. 7. (a) SCANDI neutral temperatures from the meridional chain of zones in keogram format showing the spatial distribution and time evolution. (b) Equivalent currents from the MIRACLE magnetometer chain are shown by latitude and time with large currents indicated around 08:00 UT. Both plots have overlapping coverage in latitude and time highlighted.

\subsection{EISCAT Svalbard Radar}

Several experimental modes were used on the ESR during the period of interest on the morning of 5 December 2007. The most important of these was an experiment run on the $32 \mathrm{~m}$ dish which was pointed to the NorthWest at an azimuth of $336^{\circ}$ and elevation of $30^{\circ}$ (shown in red on Fig. 1 with a circle indicating the projection at $250 \mathrm{~km}$, between zones 16 and 7). This mode was in operation from 08:15 UT to 09:00 UT. Beforehand, during the period 07:45-08:10 UT, the $32 \mathrm{~m}$ dish pointing direction was azimuth of $180^{\circ}$ and elevation of $60^{\circ}$, i.e. southward. The $42 \mathrm{~m}$ dish is fixed field-aligned and was operated during both periods. Figure 9 shows ( $a$ and e) the electron densities, (b and f) the electron temperatures, ( $\mathrm{c}$ and $\mathrm{g}$ ) the ion temperatures and ( $\mathrm{d}$ and $\mathrm{h}$ ) the ion velocities measured by both dishes of the ESR through both periods.

The electron densities $(\mathrm{Ne})$ are very low throughout the period observed. The field-aligned $42 \mathrm{~m}$ dish shows a modest increase in Ne before 07:50 UT in the E- and F-regions, and then a clear peak in low energy electron densities between 08:30-08:50 UT for the altitude region $200-300 \mathrm{~km}$. The northward looking $32 \mathrm{~m}$ dish shows high northward flows (greater than $500 \mathrm{~m} / \mathrm{s}$ ) for a brief period from the beginning of this observation mode at 08:15 UT to 08:25 UT. Otherwise the LOS plasma flows are small. The $42 \mathrm{~m}$ dish ion temperatures ( $\mathrm{Ti}$ ) remain low, but the $32 \mathrm{~m}$ dish shows a sharp rise in Ti reaching $3000 \mathrm{~K}$, corresponding to the burst of plasma velocity, before dropping to around $1000 \mathrm{~K}$. This is still much higher than before 08:10 UT, when the Ti values observed to the South with the $32 \mathrm{~m}$ dish were of the order of $500 \mathrm{~K}$.

\section{Discussion}

Figures 2 and 3 demonstrate the correspondence of a shortlived positive excursion in the IMF $B_{z}$-component measured by the ACE satellite with a short burst of geomagnetic activity that is highly localised to the north of LYR as measured by the IMAGE magnetometer chain. This is consistent with the overdraping of a lobe field line when the Earth's magnetic dipole is tilted towards or away from the Sun, as would be the case in December. Under such a configuration magnetic merging is possible with the Earth's field lines from the polar cap region, driving a localised ionospheric flow (e.g. Crooker, 1992). While the exact timing of the impact of such features in the upstream solar wind data to the upper atmosphere is subject to significant uncertainties, especially with a draped IMF configuration, the close correspondence between the morphology of the IMF data to the ground magnetometers lend confidence in this case.

Figures 4, 5 and $7 \mathrm{a}$ demonstrate the timing and extent of perturbations to the thermosphere, as observed by the SCANDI and FPI instruments, resulting from the changes to the magnetosphere-ionosphere system. The large increases in ion velocity evident correspond to rapid and significant changes to both neutral velocities and temperatures, that are also spatially localised. The significance of these features is the demonstration of the ability of the thermosphere to respond to imposed changes extremely rapidly over a small region of the atmosphere.

Figures 8 and 9 demonstrate the impact of the resulting electric fields on ionospheric velocities as measured by both the EISCAT and Cutlass Finland radars. The peak in radar 
(a)

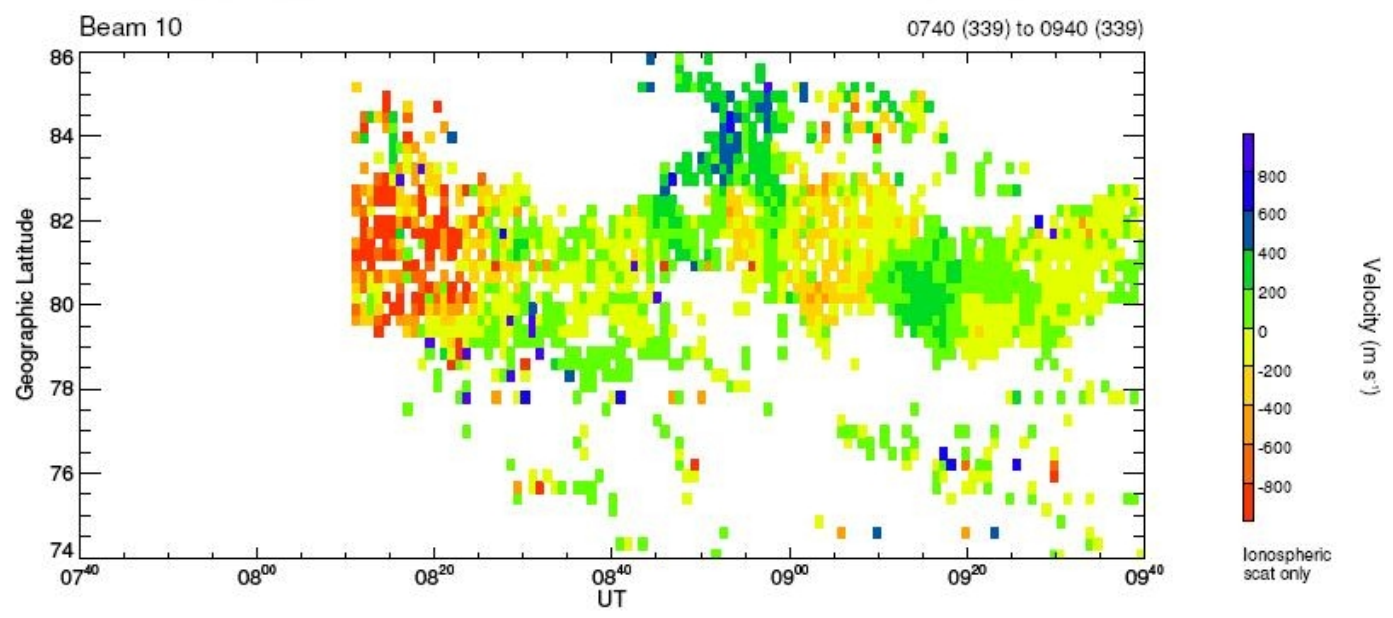

(b)

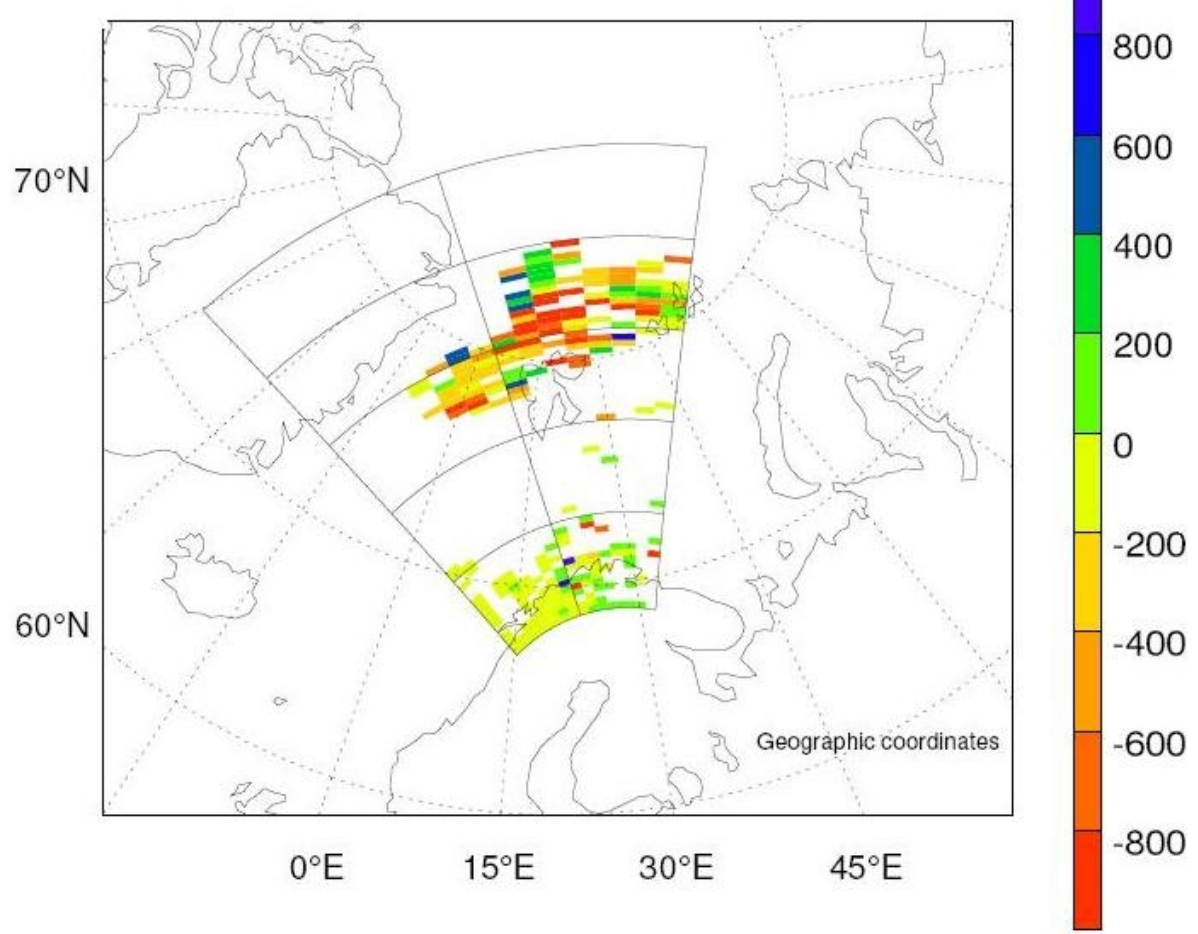

Fig. 8. CUTLASS radar ion velocities from 5 December 2007 demonstrating (a) the short duration of the burst of flow, and (b) the spatially localised focus to the NNW of Svalbard at 08:15 UT.

LOS velocities appear to be from 08:10-08:22 UT as measured by the CUTLASS and EISCAT radars. However, based on the assumption that the ionospheric response over Svalbard can be traced through the local magnetometers we can attribute an onset time of 07:30 UT for the increase in ion velocities. While the onset of the large velocity enhancements observed after 07:30 UT is missing from both datasets it is apparent that both observed the relaxation of the velocities to background levels by 08:30 UT.

While the ion velocities have reverted to background levels by 08:30 UT, in the case of both the winds and temperatures the neutral response appears to become apparent at 07:45 UT and reaches a peak at around 08:20 UT. The fall back to background levels for the neutral winds appears to 
(a)

(b)
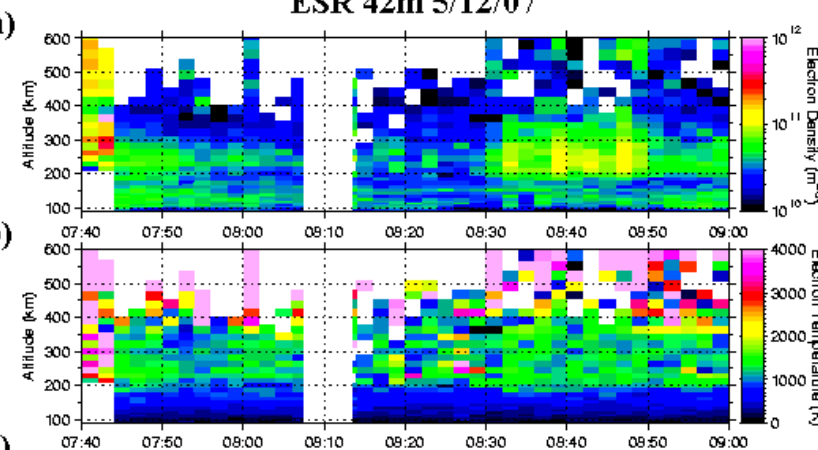

(c)

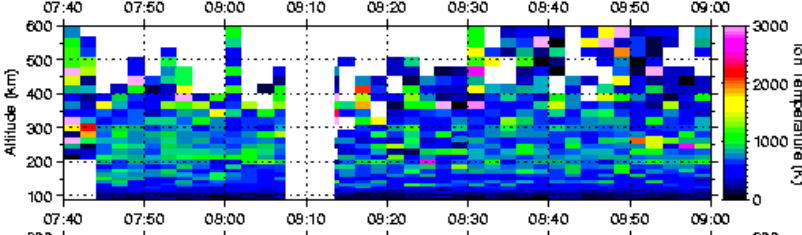

(d)

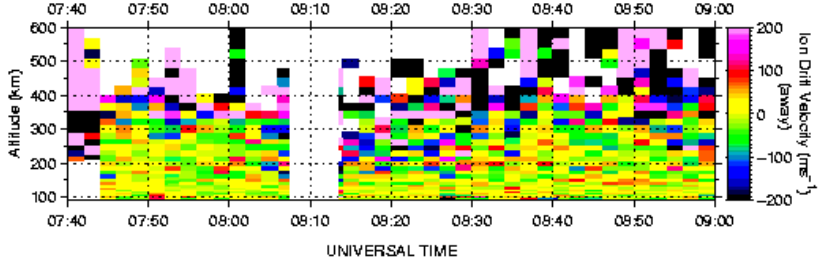

(e)

ESR 32m 5/12/07

(f)
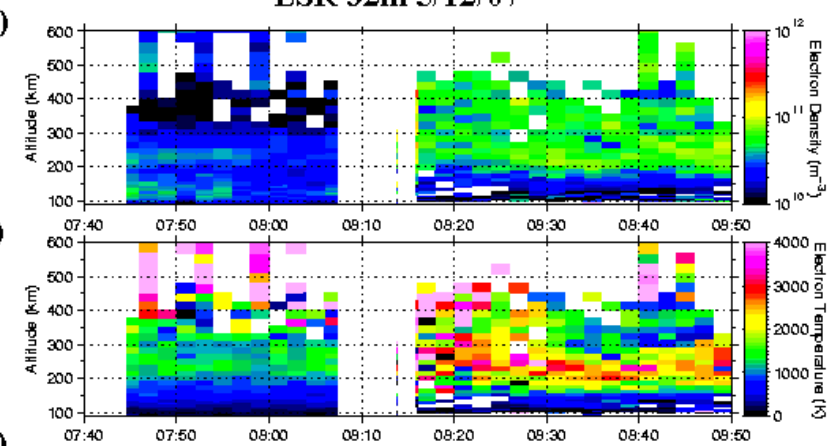

(g)

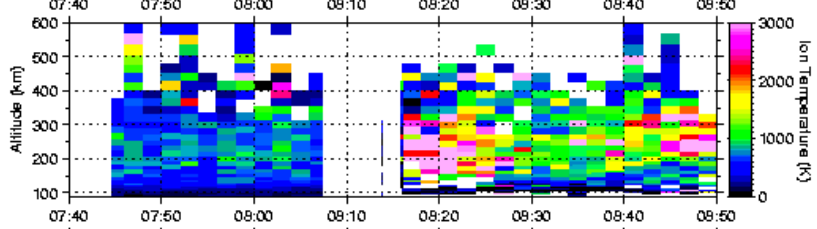

(h)

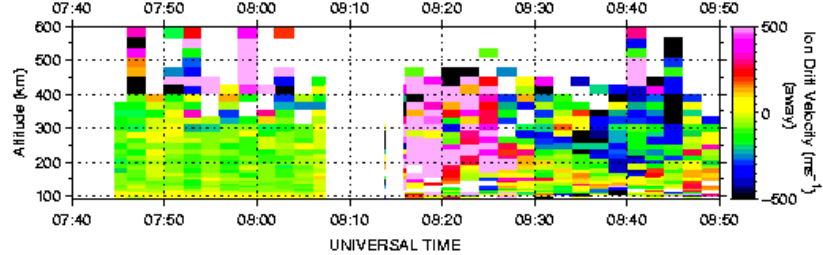

Fig. 9. ESR results from 5 December 2007 for 07:40 UT to 09:00 UT, $42 \mathrm{~m}$ is field-aligned (a-d), while the $32 \mathrm{~m}$ (e-h) points to the south before 08:10 UT and then near north afterwards (as indicated in Fig. 1).

be complete by $08: 45$ UT as measured by both SCANDI and the FPI. In the case of the neutral temperatures there appears to be a gradual decrease from the peak temperature which persists far longer than the changes in the winds. The neutral temperature change is exhibited over the whole of the SCANDI FOV, while the neutral wind acceleration is confined to the north sectors. Thus the response time for energy dissipation is different from that for momentum transfer.

The most widely used empirical models for thermospheric parameters have been the HWM (winds) and MSIS (temperatures) classes of model (Hedin, 1991). At high latitudes, however, both models have been shown to lack sensitivity to rapid changes in solar or geomagnetic activity, as well as poor spatial resolution. This case study demonstrates how MSIS-E neutral temperatures (Fig. 6) do not show the localised temperature peak observed by the SCANDI and FPI, which was caused by a short-lived burst of geomagnetic activity less than 20 min long. This is because changes in geomagnetic activity and solar flux drivers are represented in the MSIS model by the use of $3 \mathrm{~h}$ averages in the form of F10.7 and $A_{p}$ indices.

As better coordination between complementary ionospheric and thermospheric experiments reveals the details of ion-neutral coupling and improved instrumentation delivers better spatial and temporal resolution it should be possible to parameterise the local and rapid response of the thermosphere in a more realistic way.
In the context of numerical modelling the impact of rapid and local changes in thermospheric parameters has recently been noted and identified as an important aspect of the future development of the coupled thermospheric-ionospheric global circulation models (e.g. Demars and Schunk, 2007). Large systematic differences between model outputs can be demonstrated when consideration of mesoscale structure is included, e.g. in neutral temperatures by Dobbin et al. (2006), and it is apparent from comparisons with large datasets that other parameters such as wind velocities are systematically mis-represented by the models (Griffin et al., 2004). The efforts therefore to determine the extent and characteristics of mesoscale thermospheric structure as a result of ion-neutral coupling have significant impacts for the development of reliable models with which to assess properly areas such as space weather (Fuller-Rowell et al., 2006) and non-hydrostatic equilibrium scenarios.

\section{Conclusions}

The results presented in this paper have demonstrated a rapid and local thermospheric response to ionospheric forcing which challenges the accepted view of the thermosphere as a relatively viscous and slow-moving sink of energy directed into the region through magnetosphere-ionosphere coupling. By following the likely causative timeline from solar wind perturbation through magnetospheric impact and 
consequent ionospheric disturbance, the driving mechanism behind the observed thermospheric features can be identified. Both the neutral winds and temperatures appear to respond within $15 \mathrm{~min}$ to this forcing and the duration of the event appears to be closely matched across magnetospheric, ionospheric as well as thermospheric parameters. It appears that in the case of this spatially localised, short-lived event the thermosphere displays a short lag time both on the rising and falling side of the disturbance, as opposed to the inertia displayed as a "flywheel" effect that can be observed for instance on the large-scale with thermospheric winds driven by sustained ionospheric forcing.

The implications of these results are important in terms of further development of the self-consistent 3-D numerical models of the coupled ionosphere and thermosphere. Unless the true response times of the thermospheric parameters, which varies for different spatial scale lengths, are established and tested within these models there will remain a fundamental limitation on their usefulness in understanding the global response to geomagnetic forcing.

This is the first paper to combine the results of extended fields of both ion and neutral velocities, taking advantage of the colocation of relevant instruments. It is hoped in the future to extend these studies of ion-neutral coupling over extended spatial samples to investigate the nature and timing of other geophysical events and establish consistency in terms of the mesoscale structure observed in the thermosphere and its representation within the numerical models.

Acknowledgements. The authors would like to acknowledge the UK Particle Physics and Astronomy Research Council who have supported the SCANDI and FPI instruments and also the EISCAT Scientific Association who operate the ESR radar. EISCAT is supported by Finland (SA), France (CNRS), Germany (MPG), Japan (NIPR), Norway (NAFN), Sweden (NFS), and the United Kingdom (PPARC and STFC). We also acknowledge and thank Dr Mark Conde for assistance in the production of the SCANDI instrument and provision of analysis algorithms, and also Yasunobu Ogawa for providing the relevant EISCAT data. We thank Tim Yeoman for providing the Cutlass data used. We thank the ACE SWEPAM instrument team and the ACE Science Center for providing the ACE data. We thank the institutes who maintain the IMAGE Magnetometer Array.

Topical Editor M. Pinnock thanks M. J. Kosch and another anonymous referee for their help in evaluating this paper.

\section{References}

Aruliah, A. L. and Griffin, E.: Evidence of meso-scale structure in the high-latitude thermosphere, Ann. Geophys., 19, 37-46, 2001, http://www.ann-geophys.net/19/37/2001/.

Aruliah, A. L., Griffin, E. M., McWhirter, I., Aylward, A. D., Ford, E. A. K., Charalambous, A., Kosch, M. J., Davis, C. J., and Howells, V. S. C.: First tristatic studies of meso-scale ion-neutral dynamics and energetics in the high-latitude upper atmosphere using collocated FPIs and EISCAT radar, Geophys. Res. Lett., 31, L03802, doi:10.1029/2003GL018469., 2004.
Aruliah, A. L., Griffin, E. M., Aylward, A. D., Ford, E. A. K., Kosch, M. J., Davis, C. J., Howells, V. S. C., Pryse, S. E., Middleton, H. R., and Jussila, J.: First direct evidence of meso-scale variability on ion-neutral dynamics using co-located tristatic FPIs and EISCAT radar in Northern Scandinavia, Ann. Geophys., 23, 147-162, 2005, http://www.ann-geophys.net/23/147/2005/.

Burnside, R. G., Tepley, C. A., and Wickwar, V. B.: The $\mathrm{O}(+)-$ $\mathrm{O}$ collision cross-section - Can it be inferred from aeronomical measurements?, Ann. Geophys., 5, 343-349, 1987.

Codrescu, M. V., Fuller-Rowell, T. J., Foster, J. C., Holt, J. M., and Cariglia, S. J.: Electric field variability associated with Millstone Hill electric field model, J. Geophys. Res., 105, 52655273, 2000.

Conde, M. and Smith, R. W.: Phase compensation of a separation scanned, all-sky imaging Fabry-Perot spectrometer for auroral studies, Appl. Optics, 36, 5441-5450, 1997.

Crooker, N. U.: Reverse Convection, J. Geophys. Res., 97(A12), 19363-19372, 1992.

Davis, C. J., Farmer, A. D., and Aruliah, A.: An optimised method for calculating the $\mathrm{O}^{+}-\mathrm{O}$ collision parameter from aeronomical measurements, Ann. Geophys., 13, 541-550, 1995, http://www.ann-geophys.net/13/541/1995/.

Demars, H. G. and Schunk, R. W.: Thermospheric response to ion heating in the dayside cusp, J. Atmos. Solar-Terr. Phys., 69, 6, doi:10.1016/j.jastp.2006.11.002, 2007.

Dobbin, A. L., Griffin, E. M., Aylward, A. D., and Millward, G. H.: 3-D GCM modelling of thermospheric nitric oxide during the 2003 Halloween storm, Ann. Geophys., 24, 2403-2412, 2006, http://www.ann-geophys.net/24/2403/2006/.

Fuller-Rowell, T. J., Moffett, R. J., Quegan, S., Rees, D., Codrescu, M. V., and Millward, G. H.: A Coupled ThermosphereIonosphere Model (CTIM), in: STEP Handbook on Ionospheric Models, edited by: Schunk, R. W., Utah State University, Logan, UT, 1996.

Fuller-Rowell, T. J., Codrescu, M. V., Minter, C. F., and Strickland, D.: Application of thermospheric general circulation models for space weather operations, Adv. Space Res., 37, 401-408, 2006.

Griffin, E. M., Aruliah, A., Müller-Wodarg, I. C. F., and Aylward, A.: Comparison of high-latitude thermospheric meridionalwinds II: combined FPI, radar and model Climatologies, Ann. Geophys., 22, 863-876, 2004, http://www.ann-geophys.net/22/863/2004/.

Griffin, E. M., Aruliah, A. L., McWhirter, I., Yiu, H.-C. I., Charalambous, A., and McCrea, I.: Upper thermospheric neutral wind and temperature measurements from an extended spatial field, Ann. Geophys., 26, 2649-2655, 2008, http://www.ann-geophys.net/26/2649/2008/.

Hedin, A. E.: Extension of the MSIS Thermospheric Model into the Middle and Lower Atmosphere, J. Geophys. Res., 96, 1159$1172,1991$.

Hedin, A. E., Spencer, N. W., Biondi, M. A., Burnside, R. G., Hernandez, G., and Johnson, R. M.: Revised global model of thermosphere winds using satellite and ground-based observations, J. Geophys. Res., 96, 7657-7688, 1991.

Heelis, R. A., McEwen, D., and Guo, W.: Ion and neutral motions observed in the winter polar upper atmosphere, J. Geophys. Res., 107(A12), 1476, doi:10.1029/2002JA009359, 2002.

Lühr, H.: The Image Magnetometer Network. STEP International, 
4(10), 4-6, 1994.

MSIS-E website: http://omniweb.gsfc.nasa.gov/vitmo/msis_vitmo. html, last access 2009.

Rees, M. H. and Roble, R. G.: Excitation of O(1D) Atoms in Aurorae and Emission of the [OI] 6300-A Line, Can. J. Phys., 64, 1608-1613, 1986.

Roble, R. G.: The NCAR thermosphere-ionosphere-mesosphereelectrodynamics general circulation model, in: STEP Handbook on Ionospheric Models, edited by: Schunk, R. W., Utah State University, Logan, UT, pp. 207-216, 1996.
Yeoman, T. K., Davies, J. A., Wade, N. M., Provan, G., and Milan, S. E.: Combined CUTLASS, EISCAT and ESR observations of ionospheric plasma flows at the onset of an isolated substorm, Ann. Geophys., 18, 1073-1087, 2000,

http://www.ann-geophys.net/18/1073/2000/. 